\title{
Effects of ceranib-2 on cell survival and TNF-alpha in colon cancer cell line
}

\author{
Baspinar $\mathrm{M}^{1}$, Ozyurt $\mathrm{R}^{2}$, Kus $\mathrm{G}^{3}$, Kutlay $\mathrm{O}^{2}$, Ozkurt $\mathrm{M}^{2}$, Erkasap $\mathrm{N}^{2}$, Kabadere $\mathrm{S}^{2}$, \\ Yasar $\mathrm{NF}^{1}$, Erkasap $\mathrm{S}^{1}$ \\ Department of Physiology, Eskisehir Osmangazi University Medical Faculty, Eskisehir, Turkey. \\ nerkasap@gmail.com
}

\begin{abstract}
OBJECTIVE: The aim of this study was to investigate the effects of a novel anti-cancer drug, ceranib-2, which targets the acid ceramidase, in human colon cancer cell line.

MATERIALS AND METHODS: The cell lines were treated with $50 \mu \mathrm{M}$ of ceranib-2. Relative mRNA expression of TNF-alpha, TNF-R1 and ASAH were assessed by quantitative RT-PCR. RESULTS: Ceranib-2 reduced cell viability in a dose-dependent manner and the apoptotic values of cells following treatment with the dose of 50 $\mu \mathrm{M}$ were reduced significantly both at $24 \mathrm{~h}$ and $48 \mathrm{~h}$ compared to the control cells $(p<0.001)$. TNF-alpha receptor 1 (TNF-R1) mRNA levels were reduced significantly in the cell lines treated with both $25 \mu \mathrm{M}$ and $50 \mu \mathrm{M}$ of ceranib-2 for $24 \mathrm{~h}$ compared to the control cells $(p<0.05)$, whereas the difference between the treatment and the control cell lines diminished at $48 \mathrm{~h}$. The human acid ceramidase gene (ASAH) mRNA levels were significantly higher in the cell lines treated with $50 \mu \mathrm{M}$ of ceranib-2 for $48 \mathrm{~h}$ than in the other cell lines $(p<0.001)$. CONCLUSION: The study shows that ceranib-2 increased apoptosis by inducing ASAH expression and reduced TNF-R1 expression in human colon cancer cell lines in a dose and time-dependent manner (Fig. 3, Ref. 17). Text in PDF www.elis.sk.

KEY WORDS: ceranib-2, ceramide, ceramidase, colon cancer.
\end{abstract}

\section{Introduction}

Ceramides, a type of the sphingolipids, in the cell membranes may be produced either by the breakdown of sphingomyelin or glycosphingolipids, by the condensation of serine and palmitoylCoA or by the dephosphorylation of ceramide-1-phosphate (S1P) (1). Hydrolysis of ceramide by ceramidase yields in the formation of sphingosine. Ceramides potentiate cellular proliferation and differentiation and pro-apoptotic activity in cancer cells (2). Therefore, defects in ceramide synthesis and signaling have been implicated in cancer pathophysiology $(3,4)$. It has been suggested that over-expression of ceramidases is associated with an increased resistance to apoptosis, which results in poor prognosis in several types of cancer including melanoma, prostate cancer, head and neck cancers $(5,6)$. Entirely, these findings indicate that ceramidases are potential targets in cancer therapy. Despite the known actions of sphingolipid-mediated signaling in cancer cells, the effects of ceramidase inhibition are poorly understood.

${ }^{1}$ Department of Physiology, ${ }^{2}$ Department of General Surgery, Eskisehir Osmangazi University Medical Faculty, and ${ }^{3}$ Anadolu University, Open Faculty, Department of Health Program, Eskisehir, Turkey

Address for correspondence: $\mathrm{N}$. Erkasap, MD, PhD, Department of Physiology, Eskisehir Osmangazi University Medical Faculty, Eskisehir, Turkey.

Acknowledgements: This study was supported by a grant (project number: 2012/11032) from Eskisehir Osmangazi University Scientific Research Projects Committee.
It has been reported that colorectal cancer (CRC) cells showed a $>50 \%$ decrease in ceramide levels, when compared with normal cells in colon mucosa (7). Actually, ceramide has an important role in the response to chemotherapy in CRC (8). Inhibition of ceramidase activity by ceranib-2 may induced apoptosis in CRC cells by the activation of ceramide levels. Despite that ceranib-2 appears promising as a chemotherapeutic in some cancer cells (9), little is known about the role of the sphingolipid rheostat on its actions, and particularly in CRC.

The present study was designed to investigate the effects of ceranib-2 on the viability of human CRC cells as well as TNF- $\alpha$, TNF-R1 and ASAH (acid ceramidase) expressions. It reveals for the first time the sphingolipid pathway as a target of ceranib-2 in $\mathrm{CRC}$.

\section{Materials and methods}

The human colon cancer cell line Caco-2 (the American Type Culture Collection - ATTC; Rockville, MD) was cultured in Dulbecco's modified Eagle's medium (DMEM, Sigma; St. Louis, MO) containing $10 \%$ fetal bovine serum (FBS), $100 \mathrm{U} / \mathrm{mL}$ penicillin, and $100 \mu \mathrm{g} / \mathrm{mL}$ streptomycin. Ceranib-2 (Cayman Chemical, MI) solution was dissolved in dimethyl sulfoxide (DMSO, Sigma) and DMEM was applied for optimal dilution.

Test groups were assigned as followed: control (untreated medium), DMSO (0.01\%, control for solvent) and six different doses $(1,2,5,10,25,50 \mu \mathrm{M})$ of ceranib-2. 


\section{1-393}

\section{Cell survival}

Following detachment with $0.25 \%$ trypsin+EDTA (Sigma), cultured cells were centrifuged at $1200 \mathrm{rpm}$ and $4{ }^{\circ} \mathrm{C}$ for $5 \mathrm{mi}$ nutes and counted with a CEDEX (Roche; Mannheim, Germany) cell counter, seeded overnight in 96 well plates (approximately $10^{4}$ cells per $0.25 \mathrm{~mL}$ ). The medium was then removed and replaced with either $250 \mu \mathrm{L}$ of untreated medium (the control) or with ceranib-2 ( 1 to $50 \mu \mathrm{M})$ for 24 or $48 \mathrm{~h}$. The effects of ceranib-2 on colon cancer cell survival were determined by 3-3-(4,5-D-methylthiazol-2-yl)-2,5-diphenyltetrazolium bromide, thiazolyl blue (MTT) test (Mossmann 1983). The optical density read at $550 \mathrm{~nm}$ with a microplate reader (BioTek; Winooski, VT) from the treated wells was converted to a percentage of living cells against the control using the following formula:

Absorbance of treated cells in each well x 100 / the mean absorbance of control cells.

RNA extraction and determination of TNF-alpha, TNF-R1 and ASAH mRNA levels by $q-P C R$

The expression of TNF-alpha, TNFR1 and ASAH mRNA was examined in control and ceranib-2 treated Caco- 2 cells. The mRNA levels of TNF-alpha, TNFR1 and ASAH in relation to the housekeeping gene were determined by qT-PCR with TaqMan probes. RT-PCR data were collected using the Roche lightcycler nano system. Gene expression levels were reported using the median as a point estimator and the range of values.

\section{Statistical analysis}

A minimum of three independent assays were used to calculate the mean results. The $p$ value $<0.05$ was considered statistically significant. The data are expressed as the mean percent fraction of the control \pm standard error of mean. Both one-way variance analysis and Tukey's multiple comparison tests were used to determine statistical significance. RT-PCR results were calculated by using the GraphPad software program. Transcript data were expressed relative to the control (set to 1 ) \pm standard deviation. Following the determination of TNF-alpha, TNF-R1 and ASAH mRNA expression using beta-actin as a reference gene, the data obtained from RT-PCR were calculated using the formula $2^{-\Delta \Delta C t}$.



Fig. 1. MTT analysis results for Caco-2 cells treated with different concentrations of ceranib-2 for 24 or $48 \mathrm{~h}$.

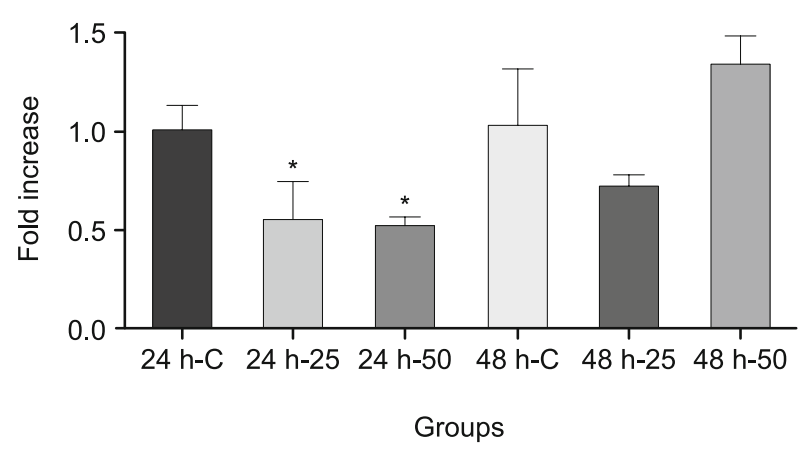

Fig. 2. TNF-alpha receptor mRNA expression.

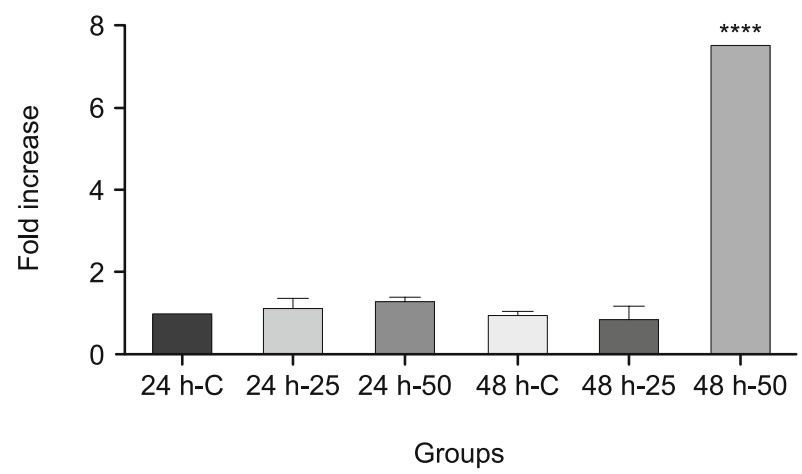

Fig. 3. ASAH mRNA expression.

\section{Results}

\section{Cell viability assays}

Viability of Caco-2 cell lines treated with 6 different concentrations of ceranib-2 for 24 and $48 \mathrm{~h}$ was tested. Either DMSO (solvent) or untreated medium (control) did not significantly change the cell survival rate. Following treatment with $0.1,1,5,10,25$ and $50 \mu \mathrm{M}$ ceranib-2, the percentages of living Caco-2 cells (against the control) were reduced to $95.2 \%(\mathrm{p}>0.5), 86.5 \%(* \mathrm{p}<0.05), 80.8 \%$ $(* * \mathrm{p}<0.01), 77.4 \%, 57.7$ and $53 \%(* * * \mathrm{p}<0.001)$ after $24 \mathrm{~h}$, and $89.4 \%(\mathrm{p}>0.5), 84.7 \%(* \mathrm{p}<0.05), 80.4 \%(* * \mathrm{p}<0.01), 72.7 \%$, 55.6 and $47.5 \%(* * * \mathrm{p}<0.001)$ after $48 \mathrm{~h}$ (Fig 1), respectively.

\section{Gene expression}

TNF-R1 mRNA levels were reduced significantly in cell lines treated with both $25 \mu \mathrm{M}$ and $50 \mu \mathrm{M}$ of ceranib- 2 for $24 \mathrm{~h}$ compared to control cells $(\mathrm{p}<0.05)$, whereas the difference between the treatment and control cell lines was diminished at $48 \mathrm{~h}$ (Fig 2). ASAH mRNA levels were significantly higher in cell lines treated with $50 \mu \mathrm{M}$ of ceranib-2 for $48 \mathrm{~h}$ than in the other cell lines $(\mathrm{p}<0.001)$ (Fig 3).

\section{Discussion}

Acid ceramidase catalyzes the hydrolysis of ceramide, a potent biological messenger molecule that induces apoptosis, inhibits 
cellular proliferation and differentiation (10). Sphingosine (Sph) is only formed from ceramide by ceramidase-catalyzed hydrolysis and can be phosphorylated by sphingosine kinases (SphKs) to form S1P. Many studies in various cancer types confirmed our original observation that overexpression of SphK1 and increased S1P production promoted cell growth (11). Considering all this information, it should not be surprising that these enzymes have also been involved in cancer progression, proliferation and inflammation $(12,13)$ and, thus may provide novel approaches to therapy of cancer (14).

Current research indicates that ceramidase inhibition may stimulate proapoptotic signaling by limiting the conversion of ceramide to S1P, which resulted in ceramide accumulation (15). Consistent with these results, Draper et al (16) reported that ceranib-2 inhibited cell proliferation in human ovarian adenocarcinoma cell line SKOV3, with an IC50 of $28 \mu \mathrm{M}$. The present study suggests that ceranib-2 promotes cell death in human colon tumor cell lines at comparatively lower doses.

According to our results, TNF-alpha receptor 1 (TNFR1) mRNA levels were reduced significantly in cell lines treated with both $25 \mu \mathrm{M}$ and $50 \mu \mathrm{M}$ of ceranib-2 for $24 \mathrm{~h}$ compared to control cells, while the difference between the treatment and control cell lines diminished at $48 \mathrm{~h}$. This suggests that TNFR1 expression may be reduced in time and dose dependently. Peng $\mathrm{C}$ et al reported that the decrease in TNFR-1 expression in ovarian cancer cells led to a decrease in cell proliferation (17). It is similar to our study, MTT levels were reduced in cell lines treated with both 25 $\mu \mathrm{M}$ and $50 \mu \mathrm{M}$ of ceranib- 2 at $24 \mathrm{~h}$.

To the best of our knowledge, our study is the first one investigating the effects of ceranib-2 treatment on ASAH gene expression. We have observed that ASAH mRNA levels were significantly higher in cell lines treated with $50 \mu \mathrm{M}$ of ceranib-2 for $48 \mathrm{~h}$ than in the other cell lines, which might be caused by time-dependent changes or by some other reactions, which resulted in the activation of sphingosine known as antiapoptotic lipid. It suggests that, the in vitro treatment of colon cancer cell line (Caco-2) using six different concentrations of ceranib-2, cell viability was reduced in the presence of a ceramidase inhibitor dose-dependently.

\section{Conclusion}

Our study shows that ceranib-2 has strong dose and time dependent anti-cancer effects and ceranib-2 might have some other effects on the pathways in the cancer pathogenesis. In addition, some other reactions, which resulted in formation of sphingosine by breakdown of ceramide with ceramidase might have an effect on apoptosis. In our future studies, we will focus on other possible effects of ceranib-2 on different pathways to explain our present results.

\section{References}

1. Schuchman H. Acid ceramidase and the treatment of ceramide diseases: The expanding role of enzyme replacement therapy. Biochimica et Biophysica Acta 2016; 1862; 1459-1471.
2. Liu J, Beckman BS, Foroozesh, M. A review of ceramide analogs as potential anticancer agents. Future Med Chem 2013; 5 (12): 1405-1421.

3. Norris JS, Bielawska A, Day T, El-Zawahri A, ElOjeimy S, Hannun Y et al. Combined therapeutic use of AdGFPFasL and small molecule inhibitors of ceramide metabolism in prostate and head and neck cancers: a status report. Cancer Gene Ther 2007; 13: 1045-1051.

4. Musumarra G, Barresi V, Condorelli DF, Scire S. A bioinformatic approach to the identification of candidate genes for the development of new cancer diagnostics. Biol Chem 2003; 384 (2): 321-327.

5. Strelow A, Bernardo K, Adam-Klages S, Linke T, Sandhoff K, Krönke $\mathrm{M}$ et al. Overexpression of Acid Ceramidase Protects from Tumor Necrosis Factor-Induced Cell Death. Exp Med 2000; 192 (5): 601-612.

6. Mahdy AE, Cheng JC, Li J, Elojeimy S, Meacham WD, Turner LS et al. Upregulation in Prostate Cancer Cells Confers Resistance to Radiation: AC Inhibition, a Potential Radiosensitizer. Mol Ther 2009; 17(3): 430-438.

7. Selzner M, Bielawska A, Morse MA, Rüdiger HA, Sindram D, Hannun YA et al. Induction of apoptotic cell death and prevention of tumor growth by ceramide analogues in metastatic human colon cancer. Cancer Res 2001; 61 (3): 1233-1240.

8. García-Barros M, Coant N, Truman JP, Snider AJ, Hannun YA. Sphingolipids in colon cancer. Biochim Biophys Acta 2014; 1841 (5): 773-782.

9. Kus G, Kabadere S, Uyar R, Kutlu HM. Induction of apoptosis in prostate cancer cells by the novel ceramidase inhibitor ceranib-2. In Vitro Cell Dev Biol Anim 2015; 51 (10): 1056-1063.

10. Seelan RS, Qian C, Yokomizo A, Bostwick DG, Smith DI, Liu W. Human acid ceramidase is overexpressed but not mutated in prostate cancer. Genes Chromosomes Cancer 2000; 29 (2): 137-146.

11. Hait NC, Oskeritzian CA, Paugh SW, Milstien S, Spiegel S. Sphingosine kinases, sphingosine 1-phosphate, apoptosis and diseases. Biochim Biophys Acta 2006; 1758 (12): 2016-2026.

12. Horton JW. Tumor necrosis factor-alpha, sphingosine, ceramide: which is the appropriate marker of inflammation? Crit Care Med 1999; 27 (11): 2580-2581.

13. Nemoto S, Nakamura M, Osawa Y, Kono S, Itoh Y, Okano Y et al. Sphingosine kinase isoforms regulate oxaliplatin sensitivity of human colon cancer cells through ceramideaccumulation and Akt activation. J Biol Chem 2009; 284 (16): 10422-10432.

14. Canals D, Perry DM, Jenkins RW, Hannun YA. Drug targeting of sphingolipid metabolism: sphingomyelinases and ceramidases. Br J Pharmacol 2011; 163 (4): 694-712.

15. Liu X, Cheng JC, Turner LS, Elojeimy S, Beckham TH, Bielawska A et al. Acid ceramidase upregulation in prostate cancer: role in tumor development and implications for therapy. Expert Opin Ther Targets 2009; 13 (12): 1449-1458.

16. Draper JM, Xia Z, Smith RA, Zhuang Y, Wang W, Smith CD. Discovery and evaluation of inhibitors of human ceramidase. Mol Cancer Ther 2011; 10 (11): 2052-2061.

17. Peng C, Su J, Zeng W, Zhang X, Chen X. TNFR-1 regulates ovarian cancer cell tumorigenicity through PIK3CB-p110BETA. Curr Mol Med 2015; 15: 487-496.

Received February 28, 2017. Accepted March 13, 2017. 